\title{
场域与叙事一一红色文化融入大学生理想信念教育的 路径研究
}

\author{
张 欢* 陈 霆 \\ 海南师范大学, 海南 571158
}

\begin{abstract}
摘 要：海南拥有 “23 年红旗不倒”的光辉革命战绩，拥有丰富的红色文化资源，海南高校应把海南红色文化作 为塑造当地大学生理想信念的重要资源，通过转变场域，如构建红色教育基地，“抗战老兵口述史”调研活动等方式， 增强红色文化的实践性和接受度; 通过改变叙事模式, 挖掘撰写红色资源校本教材, 形成海南红色文化融入大学生理 想信念教育的融通机制。
\end{abstract}

关键词：红色文化; 理想信念; 当地大学生

\section{Field and Narrative_ _ The Path of Integrating Red Culture into College Students' Ideal and Faith Education}

\author{
Huan Zhang*, Ting Chen \\ School of Marxism at Hainan Normal University, Haikou, Hainan 571158, China
}

\begin{abstract}
Hainan has a glorious revolutionary record of " 23 years of red flag does not fall" and has rich red cultural resources. Hainan colleges and universities should regard Hainan red culture as an important resource for shaping the ideals and beliefs of local college students, by transforming the field, such as building red education. Base, "research history of anti-war veterans" research activities, etc., to enhance the practice and acceptance of red culture; through the change of narrative mode, to explore the red resource school-based textbooks, to form a fusion mechanism for the integration of Hainan red culture into the ideal and belief of college students.
\end{abstract}

Keywords: Red culture; ideals and beliefs; local college students

一、引言

中共中央、国务院《关于进一步加强和改进大学生思想政治教育的意见》中强调, 加强和改进大学生思想政治教 育工作要以 “理想信念教育为核心” , “开展中国革命、建设和改革开放的历史教育”。红色文化融人到大学生到社 会实践和课堂教学, 对于加强和改进大学生思想政治教育, 坚定大学生对中国特色社会主义理想信念的信仰, 促使大 学生践行社会主义核心价值观等都具有十分重要的作用。

海南高校应深人发掘海南本土红色文化资源, 让海南文化走进海南高校, 将红色文化融人到当地大学生的思想政 治教育其中, 将大学生的理想信念塑造同红色文化有机的结合起来, 有利于帮助大学生树立正确的三观; 有利于大学 生了解海南、热爱海南、服务海南、奉献海南; 有利于大学生坚定中国特色社会主义的道路自信，坚定其对国家的自 信和对社会主义理想信念的追求。

\section{二、海南红色文化积淀的精神信仰}

地理和历史条件决定了海南有着丰富的红色文化资源。琼崖红军云龙改编旧址、李硕勋烈士纪念碑、母瑞山革命 根据地纪念园、冯白驹将军纪念亭、红色娘子军雕像、临高角解放海南纪念园, 生动形象的展现了在革命战争期间, 海南人民在中国共产党的领导下，在极其艰苦的环境下英勇奋斗，努力拼搏，坚持 “23年红旗不倒的” 伟大业绩。琼 崖革命斗争史陈列馆, 记录了琼崖特委在不同时期开展的活动, 展现了琼崖人民在以冯白驹、王国兴等一批共产党员

*通讯作者: 张欢, 1982 年 9 月, 女, 汉, 四川渠县人, 海南师范大学马克思主义学院副教授, 思政系支部书记。 研究方向：青年思想政治教育、思想政治教育史和国家文化安全研究。

基金项目：2018年度海南省哲学社会科学规划课题（思政专项）课题（项目编号：hnsz2018-16)；全国首批 “三 全育人”综合改革试点院（系）——海南师范大学马克思主义学院专项课题研究成果之一（项目编号：16)。 
的带领下, 克服孤岛作战的艰苦条件, 密切联系琼崖人民保卫自己家园的历史画卷。六连岭烈士陵园是1961年万宁县 人民政府为纪念在第一、二次国内革命斗争、抗日战争, 解放战争中牺牲的革命烈士而修建, 该陵园彰显了黎族军民 坚持 23 年, 为夺取革命胜利, 不畏牺牲, 艰苦奋斗的精神。以上种种都是海南军民在革命艰苦岁月中为维护民族的尊 严、追求自由, 不畏牺牲, 艰苦奋斗最生动形象的体现, 是不可磨灭的印记。这些宝贵的革命遗址中所凝聚的宝贵精 神, 是共产党革命精神的集中体现。

在中国革命精神体系中, 中国共产党在领导琼崖革命过程中所形成的琼崖革命精神, 可以说是一朵奇苑。聂荣瑧 曾盛赞琼崖纵队 “孤岛奋战, 艰苦卓绝, 二十三年红旗不倒”。周恩来也曾指出: “海南斗争, 坚持二十三年红旗 不倒，这是很大的成绩。”琼崖革命斗争史在中国新民主主义革命史上有其特殊的历史地位和历史使命，“琼崖革命 精神的内涵十分丰富。除 ‘冯白驹精神”、“王文明精神” 、还有被誉为 ‘红色娘子军精神”、“琼崖地下学联精 神”、“白沙起义精神” 等 ${ }^{[1]}$ 。这些精神是不仅是新时代青年学生政治认同的感性材料而且是当代大学生必须追求的 价值理念。

在新的历史条件下, 在习近平总书记 “4 - 13” 重要讲话和中央 12 号文件精神的鼓舞下, 海南的红色文化及其革 命精神信仰不仅没有过时, 反而随着时代的发展不断注人新的时代价值。

\section{三、加强大学生理想信念教育的重要性}

大学生由于其世界观、人生观和价值观都处于一个比较波动、易于受到社会、网络等环境影响的时期, 特别是在 互联网时代, 当代大学生作为网络社区的原住民, 其思想更易受到网络多元文化的影响, 因此, 如何在纷繁复杂的思 想文化中坚定社会主义和共产主义的信仰具有非常重要的意义。大学生理想信念的重要性主要体现在国家和个人两个 层面:

（一）从国家层面来看, 新时代我国的主要任务是实现中华民族的伟大复兴和在本世纪中叶实现社会主义现代 化, 而这两项伟大的任务不仅需要青年一代有坚定的理想信念, 同时还需付出艰辛努力。有学者认为理想信念的重要 作用主要有四个方面: 首先, 必须明确我国当代大学生需要树立什么样的理想信念是实现国家复兴的首要任务; 其 次, 大学生的理想信念必须结合我国人民现阶段的共同奋斗目标, 即两个一百年奋斗目标; 第三, 如何抵御纷繁复杂 的多元文化的侵扰, 大学生如何运用科学的理想信念坚定社会主义共产主义的信仰是关键环节; 第四, 大学生要将科 学的理想信念指导我们的日常生活, 转化为实现中华民族伟大复兴的动力 ${ }^{[2]}$ 。

(二) 从大学生个体自身特点来看, 大学生的年龄特点, 知识文化素养、人生阅历都处于快速成长发展期, 因 此, 如何引导大学生把个体荣誉与理想信念融人到国家的前途命运中去, 必须加强大学生理想信念教育。

从年龄上分析, 大学生的身心发展已到 “拔节孕穗” 期, 这个时期意的青年大学生味着对 “营养” 需求旺盛, 意 味着思想观念在逐步成熟, 意味着参与社会的积极性更高; 从知识文化素养来分析, 当代大学生有着广泛阅读范围, 有着分析解决问题的能力, 有着对不同文化的理解力; 但从人生阅历来分析, 他们虽然有着强烈的好奇心和接触各种 社会活动的经历, 但还不具备单独面对复杂问题的能力和分析理解国际事务的认识能力 ${ }^{[3]}$ 。如何运用好大学生的 “拔 节孕穗” 期, 作为新时代的思想政治课教师有着责无旁贷的责任, 通过思想政治课、形势与政策课等, 引导大学生学 会理解和辨析当今国内外局势, 冲突和矛盾, 形成坚定走中国特色社会主义道路的理想信念; 引导大学生把自身的知 识才干和梦想融人到中华民族伟大复兴的道路中，使个体的梦想融人到中国梦之中。

\section{四、海南红色文化对大学生理想信念塑造的积极意义}

首先, 海南红色文化有助于大学生形成正确的理想信念。琼崖革命造就了一大批坚定的马克思主义和信念和共产 主义伟大理想的无产阶级革命者, 在海南这样艰苦的革命环境下, 艰苦奋斗, 不怕牺牲, 坚定的为党和人民奉献自 己。新时代, 同样需要这样一种坚定的共产主义理想和马克思主义信念来激励大学生团结奋斗, 奋发进取, 为实现中 华民族伟大复兴添砖加瓦 ${ }^{[4]}$ 。不平指出: “我们一定要经常教育我们的人民, 尤其是我们的青年, 要有理想”。大 学生是拥有现代科学知识的人才群体, 即将步人社会的他们将是建设社会主义, 实现伟大中国梦的强大力量。通过红 色文化的教育熏陶，有利于大学生树立具有中国特色的社会主义共同理想和实现共产主义的最高理想。

其次, 海南红色文化有利于当代大学生继承和发扬艰苦奋斗的作风。海南环境的恶劣, 使革命具有更大的难度, 艰苦的革命环境夜市伟大的革命者在与敌人斗争时, 永远保持着艰苦奋斗的精神。即使如今的时代, 和平昌盛, 但艰 苦奋斗的精神不能丢, 其永远是推动一个民族不断向前发展的精神支柱, 是一个国家永远充满生机活力保持昂扬向上 的精神动力。面对学习更加自由自主的大学环境, 大学生更加要发扬艰苦奋斗的精神, 努力学习专业知识, 同时要更 加主动的多积累, 充实自己。在生活上, 同样也要培养自己吃苦耐劳的品质, 让自己成为更加坚强成熟, 不惧怕恶劣 环境，能够为国家奉献自己的才智，愿意到国家需要的地方服务的四有青年。 
再次, 海南红色文化有利于指导大学生更好的开展社会实践活动。作为一名新时代大学生, 生活和学习的空间更 加广泛, 我们不能仅仅满足于课堂或者书本的教学, 要能够更加积极主动的去参加各种各样的社会活动, 特别是寒 暑假的 “三下乡” 社会实践活动, 接触更多的人民群众, 更加贴切的去感受社会, 这对于深人了解国家情势和方针政 策, 具有非常重要的作用。在社会实践活动中, 大学生可以近距离的接触人民群众, 学习在校园内所学不到的知识, 去充实自己，使学校理论和社会实践结合起来，真正的做到实事求是。

最后, 海南红色文化有利于当代大学生培养团结合作的良好风尚。革命的成功, 不是一个人的努力, 而是革命者 和广大人民群众联合起来取得的胜利。当代大学生大多都是 “90后” , 更多的家中都是独生子女, 从小就养成 “唯我 独尊” 的性格, 面对一些事情, 就会显得有些 “不合群” 。海南革命能够保持 “23年红旗不倒” 这样伟大的功绩, 是 一群人努力的结果, 其中所蕴含的团结合作精神, 有利于教导大学生培养团结合作的精神, 学会更好的和他人相处, 更好的与他人沟通，把自己融人集体中，提高自己的集体荣誉感，使这个社会更加和谐，更加美丽。

\section{五、建构海南红色文化融入大学生理想信念教育的融通机制}

（一）转变场域, 构建大学与红色基地的互动教育机制

首先, 转变思政课教授的场域, 变教室为博物馆或爱国主义教育基地。当地高校和海南本地区的红色爱国主义教 育基地、历史博物馆等相关单位应密切合作, 建立长期互助稳定的合作交流关系。在海南, 冯白驹故居、临高角解放 公园、秀英炮台、海南省五指山革命根据地纪念园、红色娘子军纪念园、万宁市六连岭烈士陵园、母瑞山革命根据地 纪念园、张云逸纪念馆等, 都是国家级爱国主义教育基地, 高校通过与其建立合作关系, 定期带大学生进行实地教学 或者邀请相关单位工作人员进人高校讲解宣传本地的红色文化，才能实现有效互动 ${ }^{[5]}$ 。

其次, 转变红色文化展示的场域, 红色文化不仅仅体现在一方水土之中, 高校也可以将红色文化融人到校园文化 建设中, 将红色文化元素融人到文化设施、人文景观等硬件设施中。比如, 高校可以结合琼崖革命史, 红色娘子军等 优秀红色文化, 把课堂教学与红色文化融合。例如, 让音乐系的学生表演红色娘子军歌舞剧, 让传播学院的同学收集 撰写编排红色革命史诗，让美术学院的同学举办红色文化画展等，充分挖掘不同学院分享红色文化精神。

最后, 转变红色文化分享的场域, 充分利用好琼崖革命中可歌可泣的革命英雄事迹, 特别是还健在的老革命等, 他们都是给大学生展开理想信念教育的活 “教材” 。在学校互动机制建立的条件下, 高校可以邀请曾经参与过琼崖革 命战争的老战士来给大学生们讲讲他们的故事, 或者听革命者后代来叙述长辈的故事, 除此之外, 还可以开展各种和 海南红色文化有关的知识竞赛, 红色文化论坛等丰富多彩的活动, 吸引学生注意, 在这个过程中, 使其对海南的红色 文化有更加深人的了解, 并在潜移默化的影响中, 树立正确的理想信念 ${ }^{[6]}$ 。

（二）改变叙事模式, 提升思想政治理论课作为红色文化传播主阵地

首先, 叙事模式应从国家革命史到地方革命史的转变。高校在教授思想政治理论课程内容的同时, 还需根据海南 本地的实际情况, 组织师资力量挖掘撰写海南红色文化的校本课程, 将海南的红色文化引人高校课堂。例如, 贵州师 范大学就抓住本地资源, 在大一新生中开设与革命精神相关的必修课程, 使全校学生系统学习贵州的革命史, 全方位 的感悟贵州革命精神。

其次, 高校思想政治教育理论课是大学生进行思想政治理论教育的主阵地和主渠道, 在教学的过程中可以适当穿 插海南的红色文化, 发挥红色文化的教育功能。如在进行《中国近代史》课程的教学过程中, 有机融人琼崖革命史, 让学生在潜移默化中受到红色文化的熏陶; 在《思想道德修养与法律基础》中将中国精神与海南的红色革命传统有机 结合, 体现其中的传承与发扬; 在《马克思主义基本原理》课程上, 可以比较人类社会历史发展规律和海南革命历史 内在的必然性，让学生更真实的感受到红色文化和理想信念的真实性、科学性。

最后, 叙事模式改变不仅仅是在课堂, 学院还要充分运用现代化手段进行红色文化教育。有学者认为自媒体传播 模式主要有 “核心一边缘” 扩散传播模式、自媒体 “弱连接” 的信息互播模式、用户群 “圈子化” 信息传播模式、私 域一公域重叠的自媒体反馈模式 ${ }^{[7]}$, 因此, 要充分利用好自媒体作为信息传播的主要媒介, 学校应充分利用 “学习强 国” 等国家级APP, 对学生进行红色文化教育, 这样不仅可以让学生以便捷方式接触红色文化知识, 接受红色文化的 熏陶, 同时还能潜移默化地产生心灵上的共鸣, 从而达到理想信念教育的目的。总的来说, 理想信念教育不是一劳永 逸、轻而易举、一蹴而就的，而是一个长期学习和努力实践的过程 ${ }^{[8]}$ 。

\section{参考文献:}

[1]赵康太.琼崖革命研究六十年:回顾、反思与展望[J].海南大学学报(人文社会科学版), 2011.

[2]王钢.建设小康社会与大学生理想信念教育[J].道德与文明, 2005.

[3]刘英.论加强大学生理想信念教育的意义和原则 [J].西南民族学院学报(哲学社会科学版), 2002. 
[4]梁洁.论红色文化与大学生理想信念教育的关系 [J].教育研究, 2012,(04).

[5]王善,程川.海南黎族红色文化与社会主义核心价值体系[J].贵州民族研究, 2015,36(02):5-8.

[6]张莉,张欢。“四个自信”教育与重建大学生的社会主义政治信仰[J].中共成都市委党校学报, 2017.

[7]Zhang Huan. (2018). Construction of Ideological and Political Education in Colleges and Universities under the Evolution of the We Media Communication Mode. Educational Sciences: Theory \& Practice, 2018(6),3724-3736.

[8]刘建军.关于理想信念教育的几点理论思考[J].教学与研究, 2004(11). 